2015

Productivity and efficiency impacts of urea deep placement technology in modern rice production: An empirical analysis from Bangladesh

Rahman, Sanzidur

http://hdl.handle.net/10026.1/3781

10.1353/jda.2015.0158

The Journal of Developing Areas

Project Muse

All content in PEARL is protected by copyright law. Author manuscripts are made available in accordance with publisher policies. Please cite only the published version using the details provided on the item record or document. In the absence of an open licence (e.g. Creative Commons), permissions for further reuse of content should be sought from the publisher or author. 
SRL 14013.R1

(Revised version incorporating all comments of the referee)

TheJournalofDevelopingAreas

Volume 49 No. 3 Summer 2015, 119 - 134.

\title{
PRODUCTIVITY AND EFFICIENCY IMPACTS OF UREA DEEP PLACEMENT TECHNOLOGY IN MODERN RICE PRODUCTION: AN EMPIRICAL ANALYSIS FROM BANGLADESH
}

\author{
Sanzidur Rahman* \\ University of Plymouth, UK \\ Basanta K. Barmon \\ East West University, Bangladesh
}

\author{
Address for correspondence \\ Dr. Sanzidur Rahman \\ Associate Professor in Rural Development \\ School of Geography, Earth and Environmental Sciences \\ University of Plymouth \\ Drake Circus \\ Plymouth, PL4 8AA \\ Phone: +44-1752-585911 \\ Fax: +44-1752-585998 \\ E-mail: $\underline{\text { srahman@plymouth.ac.uk }}$
}

November 2014

Productivity and efficiency impact of Urea Deep Placement technology in modern rice production: An empirical analysis from Bangladesh

Abstract

Background and statement of the problem: 120 words

Research methodology and data: 120 words

Research findings: 120 words

Policy implications 40 words.

Rice is the most dominant field crop in Bangladesh covering $75 \%$ of the total cultivated area and consumes $80 \%$ of the total fertilizers alone. Nevertheless, the productivity of rice in Bangladesh remains one of the lowest in the world. Urea, the main source of nitrogen $(\mathrm{N})$, plays a key role in rice production, is required in large amount, is the most limited nutrient and also suffers from heavy system losses. A worldwide crisis of urea fertilizer in 2008 spurred the need to economise on its use with urgency. The Urea Deep Placement (UDP) technology is aimed at increasing $\mathrm{N}$ fertilizer use efficiency in rice production and thus holds the promise to economize on the use of a very important but finite resource (i.e., urea) while improving rice productivity. The present study econometrically measures the impact of recently introduced UDP technology on productivity and efficiency of modern rice cultivation at the farm-level in Bangladesh using a stochastic production frontier approach. Data were 
collected from Shimlagachi village in Sharsha upazilla (sub-district) of Jessore district, located $225 \mathrm{kms}$ southwest of capital Dhaka. A total of 100 farmers using UDP technology and another 100 farmers using conventional urea to produce rice in both Boro (dry winter) and Aman (monsoon) seasons were randomly selected. Detailed input-output data including socio-economic information of the farmers were collected through administering a pre-tested structured questionnaire. The survey was conducted during May-June 2013. Results reveal that net profit, productivity and technical efficiency are significantly higher for the farmers using UDP technology as compared with the conventional urea users. On average, productivity of UDP farmers is 13\% higher (estimated at $7164 \mathrm{~kg} / \mathrm{ha}$ and $5242 \mathrm{~kg} / \mathrm{ha}$ for Boro and Aman seasons, respectively) than the conventional urea users. Profitability is also significantly higher for UDP farmers (BCR estimated at 1.36 and 1.08 for Boro and Aman seasons, respectively) than the conventional urea users (BCR estimated at 1.17 and 0.99 for Boro and Aman seasons). Finally, technical efficiency is $14 \%$ higher (estimated at 0.93) for the UDP farmers. However, the relative gain from UDP technology adoption is significantly higher in Boro season as compared with Aman season. The key policy conclusion is that the UDP technology should be disseminated widely with urgency so that Bangladesh can improve its food security by significantly increasing rice productivity while at the same time economize significantly on the use of $\mathrm{N}$ fertilizer nutrient.

Key words: Urea Deep Placement technology, Urea Super Granules, profitability, stochastic production frontier, technical efficiency, modern varieties of rice, Bangladesh.

\section{JEL Classification: O33, Q18, C21.}

\section{Introduction}

Bangladesh, a predominantly agrarian economy, is characterized by one of the lowest landperson ratio of 0.05 ha and a very high population density of 1203 persons per sq $\mathrm{km}$ (World Bank, 2014). Agriculture is the single largest producing sector of the economy contributing $20.3 \%$ to the total gross domestic product (GDP) and employs $48.1 \%$ of the total labour force (BBS, 2011). However, the cultivable land area is gradually decreasing because of population growth, industrialization and other infrastructure development resulting in a decline of per capita land availability from 0.13 ha in 1960 to 0.06 ha in 2000 (Hossain et al., 2006). Although the rate of population growth has declined from $2.2 \%$ p.a. to $1.5 \%$ p.a. over the past four decades, the nation's population count is still increasing at a rate of two million persons per year (BBS, 2012), thereby exerting pressure on increasing food supply to feed the growing population.

Rice is the main staple food in Bangladesh and is likely to remain as such in the foreseeable future. About $75 \%$ of the total cultivated area is devoted to the production of rice and an estimated 13 million farm families are engaged in rice production. The government of Bangladesh has been trying to achieve self-sufficiency in food grain production since early 1970 s and has made remarkable progress through widespread adoption of a rice-based Green Revolution (GR) technology. The GR technology has been instrumental in improving productivity in many countries worldwide and is also crucial for sustaining food security in Bangladesh (e.g., Hossain, et al., 2006, Rahman, 2002). But the growth of rice output remains a central concern since there is very limited potential to expand cultivation of the arable land for rice and use of irrigation (Alauddin and Hossain, 2001; Hossain, 2002). This is because, although Bangladesh has good quality land, the yield per ha of rice is one of the lowest among the rice producing countries of the world. For example, average yield rate of rice is $5631 \mathrm{~kg} / \mathrm{ha}$ in Vietnam, $3590 \mathrm{~kg} / \mathrm{ha}$ in India, $3000 \mathrm{~kg} / \mathrm{ha}$ in Thailand and only $2933 \mathrm{~kg} / \mathrm{ha}$ in Bangladesh in 2012 (FAOSTAT, 2014). The yield is low because the technique of production is still outdated in many areas.

Production of rice is also input intensive, particularly, the modern varieties (MVs) of rice, which is dependent on the use of inorganic fertilizers and irrigation. About $80 \%$ of the total fertilizers (domestically produced and imported) are used in rice production alone (Balcombe, et.al, 2007; Bangladesh Bank, 2010). Nitrogen (N) plays a key role in rice production and is 
required in large amount. It is also the most limited nutrient in rice production and suffers from heavy system losses when applied as inorganic sources in the puddle field (Fillery et al., 1984 cited in Hasanuzzaman et al., 2009). Urea is the most widely used source of N fertilizer globally including Bangladesh. A worldwide crisis of urea fertilizer in 2008 spurred the need to economise on this widely used source of $\mathrm{N}$ fertilizer with urgency. The price of urea fertilizer increased from USD 277 per mt in August 2007 to USD 815 per mt in August 2008 (IFDC, 2009), which demonstrates the extent of crisis and the adverse effect on the cost of producing field crops dependent on urea fertilizer for higher productivity.

In Bangladesh, the cost of rice production is rising sharply which is forcing farmers to seek improved ways of production that could economise on resource use while increase productivity. Although adoption of any new technology is a risky business and takes time, some farmers are still willing to undertake measured risks in their drive to improve rice productivity and reduce production cost. Therefore, new technologies need to be found and applied widely in order to free the constraints of the closing land frontier in Bangladesh while continuing to increase rice productivity. The International Fertilizer Development Centre (IFDC. 2009, 2013) claims that the newly introduced Urea Deep Placement (UDP) technology in modern rice cultivation holds the promise to simultaneously increase rice productivity while economise on $\mathrm{N}$ fertilizer use.

Given this backdrop, the principle aim of this study is to evaluate the merits of adopting UDP technology in modern rice production at the farm-level. The specific objectives are to: (a) examine profitability of adopting UDP technology; (b) identify the impact of UDP technology on rice productivity; and (c) identify the impact of UDP technology on technical efficiency in rice production.

The paper is organized as follows. Section 2 provides a brief discussion of the UDP technology, its origin and a review of existing literature. The main purpose of the review is to examine the relative merit of UDP technology as well as to establish analytical shortcomings in the evaluation of this new technology in the literature. Section 3 presents the analytical framework, description of the study area and the data. Section 4 presents the results. Section 5 provides conclusions and draws policy implications.

\section{The Urea Deep Placement technology in rice production}

Technological change includes two components: product innovation and process innovation. The UDP technology represents more of a process innovation with some modification of the already used product, i.e., urea fertilizer, which is turned into Urea Super Granules (USG) through briquetting. The UDP technology is developed by International Fertilizer Development Centre (IFDC) after working with farmers for over 20 years, particularly in Bangladesh (IFDC, 2013). The principal aim of UDP technology is to improve $\mathrm{N}$ use efficiency in rice production which in turn is expected to improve productivity. UDP technology consists of two key components. The first is a fertilizer 'briquette' produced by compacting commercially available urea fertilizer (e.g., which is then known as Urea Super Granules or USG weighing roughly 1-3 grams per briquette). The second key component of UDP is the placement of urea briquettes (USG) below the soil surface. In irrigated rice fields, the briquettes are centred between four plants at a depth of 7-10 centimetres within seven days after transplanting. Placement can be done either by hand or with a mechanical applicator. The briquette releases $\mathrm{N}$ gradually, coinciding with the crop's requirements during the growing season (IFDC, 2013). Also, in this production process $\mathrm{N}$ fertilizer is required to be applied only once for the entire crop season unlike conventional urea 
production process when 3-4 applications are required (mainly broadcasting first and then topdressing subsequently).

IFDC (2009) noted that the UDP technology is spreading widely in Bangladesh which covered 500,000 ha of irrigated rice land and increased total rice production by 268,000 t, labour use by 9.5 days per ha and net return by USD 188 per ha by 2008 and also reduced fertilizer imports by $50,000 \mathrm{mt}$ in 2009. The Bangladesh Government, with IFDC assistance, began expanding UDP technology to about 3 million farm families on 1.5 million ha funded by USAID and the United States Department of Agriculture (USDA) from 2009 (IFDC, 2009).

The literature search on the impact of UDP technology revealed that, other than the IFDC $(2009,2013)$ reports, the literature is dominated by agronomic studies examining its impact either on $\mathrm{N}$ use efficiency or increase in grain yield from experiments or field trials. For example, Pasandaran et al. (1999) reported that UDP showed a $25 \%$ saving in $\mathrm{N}$ fertilizer rates leading to an average increase of $400 \mathrm{~kg} / \mathrm{ha}$ in rice yield in Indonesia. Similarly, Wani et al. (1999) found that among the various slow-release or modified sources of urea at different $\mathrm{N}$ levels, USG was the best in terms of grain yield enhancement $(9.5 \%$ to $33.8 \%)$ due to higher $\mathrm{N}$ use efficiency in rice production in India. Jaiswal and Singh (2001) observed that deep placement of USG effectively increased $\mathrm{N}$ use efficiency by $31.7 \%$ compared to conventionally applied urea in irrigated rice in India. Bulbule et al. (2002) reported that USG briquette applied at the rate of $56 \mathrm{~kg} \mathrm{~N} / \mathrm{ha}$ produced $25 \%$ higher yield than the recommended dose of $100 \mathrm{~kg} \mathrm{~N} / \mathrm{ha}$ using conventional urea in rice crop in India. Tarfa and Kiger (2013) reported that UDP technology increased $\mathrm{N}$ use efficiency by $40 \%$ and irrigated rice yield by $20-30 \%$ in Niger State, Nigeria in 2012.

In case of Bangladesh, Bowen et al. (2005) reported that rice yield was higher for UDP technology users than farmer's practice and the magnitude of increase was $1120 \mathrm{~kg} / \mathrm{ha}$ with a saving in applied $\mathrm{N}$ of $70 \mathrm{~kg} / \mathrm{ha}$ during Boro season (dry winter) and $890 \mathrm{~kg} / \mathrm{ha}$ with a saving in applied $\mathrm{N}$ of $35 \mathrm{~kg} /$ ha during Aman season (monsoon), respectively. The Bangladesh Rice Research Institute also noted that the use of UDP technology can minimize loss in $\mathrm{N}$ from soil and hence increase its effectiveness by 20-25\% (BRRI, 2008). Hasanuzzaman et al. (2009) reported that the application of USG@75 kg/ha produced 22.03\% more yield than conventional urea application in MV Boro rice cultivation in the experimental plots in Bangladesh.

The results from experimental studies mentioned above although provide evidence of large positive impact of UDP technology on $\mathrm{N}$ use efficiency and/or grain yield of rice, they have a number of analytical shortcomings. First, these experiments are conducted under controlled environment which may not necessarily hold in farmers' field. Therefore, the level of gains from UDP technology observed in research stations is unlikely to be realised in farmers' field. Second, no proper economic analysis is attempted in these experimental studies that could provide information on net financial gain from adopting this technology. This is because although the technology economises on $\mathrm{N}$ fertilizer use, it is more labour intensive and could increase labour cost substantially and, therefore, possibly offset benefits arising from a reduction of fertilization cost. And finally, the assumption underlying such experiments is that producers are technically efficient in their production process which is unrealistic given widespread evidence of inefficiency in farming (Bravo-Ureta et al., 2007). Technical efficiency refers to a producer's ability to obtain the highest possible output from a given quantity of inputs or to obtain a given level of output from minimum level of inputs (Rahman, 2003). Our contribution to the existing literature is that we have examined the impact of this recently introduced UDP 
technology on rice productivity and efficiency at the farm-level using established econometric procedure. Specifically, we applied the stochastic production frontier approach (SFA) which is capable of econometrically tracing the impact of UDP technology on rice productivity and technical efficiency while allowing farmers to be inefficient in their production process. We have also examined profitability of adopting UDP technology using standard Cost Benefit Analysis (CBA). Therefore, the findings of the present study are expected to provide academics, researchers, non-governmental organizations as well as policy makers with useful information on the diverse impacts of adopting UDP technology in rice production at the farm-level, which will facilitate in devising policies to improve food security in Bangladesh and elsewhere.

\section{Methodology}

In order to examine the impact of UDP technology on profitability of modern rice production, the standard Cost-Benefit Analysis (CBA) is used. Next, to examine the impact of UDP technology on rice productivity and efficiency, the SFA is applied. The details of the methods used are presented below preceded by a description of the study area and the data.

\subsection{Study area and the data}

To assess the diverse impacts of UDP technology on MV Boro rice and MV Aman rice production, Shimlagachi village in Sharsha upazilla (sub-district) of Jessore district was selected. Jessore is located at a distance of $225 \mathrm{~km}$ towards the south west of capital Dhaka, Bangladesh. The Shimlagachi village was purposively selected because the farmers in this village have adopted UDP technology using USG along with conventional urea in MV rice production. Initially, a detailed list of farmers who have adopted UDP technology and/or conventional urea in MV rice production was collected from upazilla (sub-district) agriculture office. Then a total of 100 farmers using UDP technology and another 100 farmers using conventional urea to produce rice in both Boro and Aman seasons were randomly selected. Selection of the UDP adopters and conventional urea users from the same village will provide clear information on relative advantage of this technology. This is because all farmers in the village face similar input and output prices as well as the production environment, and therefore, any observed differences could be confidently attributed to UDP technology alone. Detailed information on various inputs used and output of MV rice produced in both seasons including socio-economic information of the farmers were collected through administering a pre-tested structured questionnaire. The survey was conducted during May-June 2013.

\subsection{Profitability or Cost-Benefit Analysis}

Profitability or CBA includes calculation of detailed costs of production and returns from rice produced in Boro and Aman seasons on a per hectare basis. MV Aman rice is largely produced under rainfed condition while MV Boro rice production requires supplementary irrigation throughout.

The total cost (TC) is composed of total variable costs (TVC) and total fixed costs (TFC). TVC includes costs of human labour (both family supplied and hired labour, wherein the cost of family supplied labour is estimated by imputing market wage rate), mechanical power, seed, manure, chemical fertilizers, pesticides, and irrigation. TFC includes land rent (if owned land is used then the imputed value of market rate of land rent is applied). The gross return (GR) is computed as total rice output multiplied by the market price of rice. Profits or gross margin (GM) is defined as GR-TVC, whereas the net return (NR) is defined as GR-TC. Finally, the Benefit Cost Ratio (BCR) is computed as GR/TC.

\subsection{Analytical framework: The stochastic production frontier model}


The stochastic production frontier approach, developed by Aigner et al. (1977), is utilized in this study. This is because, in this approach, we can relax the unrealistic assumption of perfect efficiency of the farmers in their production process and identify individual farmers who are technically inefficient and their level of inefficiency in relation to their best performing peers operating at the frontier using same technology. The stochastic production frontier for the $i$ th farmer is written as:

$Y_{i}=f\left(X_{i}\right)-u_{i}+v_{i},(1)$

where $Y_{i}$ is the output, $X_{i}$ is the vector of physical inputs, $v_{i}$ is assumed to be independently and identically distributed $N\left(0, \sigma_{v}^{2}\right)$ two sided random error, independent of the $u_{i}$; and the $u_{i}$ is a nonnegative random variable $\left(u_{i} \geq 0\right)$, associated with inefficiency in production which is assumed to be independently distributed as truncation at zero of the normal distribution with mean $-Z_{i} \delta$, and variance $\sigma_{u}^{2}\left(\mid N\left(-Z_{i} \delta, \sigma_{u}^{2} \mid\right)\right.$, where $Z_{i}$ are the correlates of inefficiencies on farm $i$. In this formulation, output is assumed to be strictly monotonically increasing in physical inputs.

In determining the predictors of production efficiency, we use the single stage approach proposed by Battese and Coelli (1995) wherein the technical inefficiency parameter is related to a vector of farm-specific characteristics subject to statistical error, such that:

$u_{i}=Z_{i} \delta+\zeta_{i} \geq 0,(2)$

where, $Z_{i}$ are the farm-specific managerial and household characteristics and the error $\zeta_{i}$ is distributed as $\zeta_{i} \sim N\left(0, \sigma_{\zeta}^{2}\right)$. Since $u_{i} \geq 0, \zeta_{i} \geq-Z_{i} \delta$, so that the distribution of $\zeta_{i}$ is truncated from below at the variable truncation point, $-Z_{i} \delta$.

The production efficiency of farm $i$ in the context of the stochastic frontier production function is defined as:

$E F F_{i}=E\left[\exp \left(-u_{i}\right) \mid \xi_{i}\right]=E\left[\exp \left(-\delta_{0}-\sum Z_{i} \delta \mid \xi_{i}\right)\right.$

where $E$ is the expectation operator. This is achieved by obtaining the expressions for the conditional expectation $u_{i}$ upon the observed value of $\xi_{i}$, where $\xi_{i}=\mathrm{v}_{\mathrm{i}}-\mathrm{u}_{\mathrm{i}}$. The method of maximum likelihood is used to estimate the unknown parameters, with the stochastic frontier and the inefficiency effects functions estimated simultaneously. The likelihood function is expressed in term of the variance parameters, $\sigma^{2}=\sigma_{\mathrm{v}}{ }^{2}+{\sigma_{\mathrm{u}}}^{2}$ and $\gamma=\sigma_{\mathrm{u}}{ }^{2} / \sigma^{2}$ (Battese and Coelli, 1995).

\subsection{The empirical model}

As mentioned earlier, UDP technology is a process innovation which uses the same input of $\mathrm{N}$ fertilizer as the conventional urea users in rice production. Therefore, in empirical specification of the model, the UDP technology users can be best identified by specifying a dummy variable, which takes the value of 1 if the farmer is using UDP technology or zero otherwise. An advantage of using dummy variable is that it captures the underlying non-linear relationship of the variable with the dependent variable. For empirical specification, we use the general form of the Cobb-Douglas stochastic production frontier function ${ }^{1}$ :

$\ln Y_{i}=\beta_{0}+\sum_{j=1}^{12} \beta_{j} \ln X_{i j}+\sum_{m=1}^{4} \tau_{m} D_{i m}+\alpha_{1 i} U D P_{i}+v_{i}-u_{i}$

and

\footnotetext{
${ }^{1}$ We did not use the translog model because we are using a large number of explanatory indicators. Moreover, Kopp and Smith (1980) suggest that the choice of functional form has a limited effect on technical efficiency. Consequently, the Cobb-Douglas specification is widely used in studies (e.g., Rahman et al., 2012; Asadullah and Rahman, 2009; Rahman and Hasan, 2008).
} 
$u_{i}=\delta_{0}+\sum_{d=1}^{5} \delta_{d} Z_{i d}+\zeta_{i}$

where $Y_{i}$ is the rice output; $X_{i j}$ is $j$ th input for the ith farmer; $D_{i j}$ are the dummy variables used to account for the zero values of input use and have the value of 1 if the $j$ th input used is positive and zero otherwise ${ }^{2} ; U D P_{i}$ is the dummy variable to account for farmers using UDP technology in their production process, $v_{i}$ is the two sided random error, $u_{i}$ is the one sided half-normal error, In natural logarithm, $Z_{i d}$ variables representing socio-economic characteristics of the farm to explain inefficiency, $\zeta_{i}$ is the truncated random variable; $\beta_{0}, \beta_{j}, \tau_{m}, \alpha_{1}, \delta_{0}$, and $\delta_{d}$ are the parameters to be estimated.

A total of 12 production inputs (X) and four fertilizer user dummies (D) are used in the full specification, and 5 variables representing socio-economic characteristics of the farmer $(\mathrm{Z})$ are included in the inefficiency effects model as predictors of technical inefficiency. Accounting for the impact of UDP technology is implemented by estimating two versions of the empirical model. First, to examine its impact of UDP technology on rice productivity, the dummy variable (UDP) is included in the stochastic production frontier model (Model 1). Next, to examine its impact on technical efficiency, the UDP dummy variable is included in the inefficiency effects model (Model 2). Use of a total of 12 inputs implies that we have included all possible inputs required in the production process, thereby, reducing any potential missing variable bias. Variables included to predict technical inefficiency are based on the existing literature and justification thereof (e.g., Rahman et al., 2012; Rahman, 2010; Asadullah and Rahman, 2009; Rahman, 2003; Coelli et al., 2002; Wadud and White, 2000).

\section{Results}

\subsection{Profitability of UDP technology}

Profitability or CBA of MV rice cultivation of Boro and Aman seasons amongst UDP technology adopters and conventional urea users is presented in Table 1 . The first row provides information on the productivity of MV rice, i.e., yield per ha. The yield rate of UDP adopters is $7,164 \mathrm{~kg} / \mathrm{ha}$ and 5,242 kg/ha in Boro and Aman seasons which are $11 \%$ and $8 \%$ higher than conventional urea users, respectively. This finding confirms significant productivity advantage of UDP technology at the farm level for both seasons $(p<0.01)$, but the magnitude of yield gain is much lower than those reported from agronomic experiments in the literature (e.g., Bulbule et al., 2002; Bowen et al., 2005; Hasanuzzaman et al., 2009), as expected.

Table 1 also shows that the farmers adopting UDP technology incur significantly lower urea fertilizer cost $(\mathrm{p}<0.01)$. This is because the UDP farmers applied only $164 \mathrm{~kg} / \mathrm{ha}$ and 124 $\mathrm{kg} / \mathrm{ha}$ of USG in Boro and Aman seasons respectively, which are 50\% lower than the conventional urea users, thereby confirming significant reduction in $\mathrm{N}$ fertilizer use, a key feature of this technology. However, the farm-level application rate under UDP technology is much higher than from experiments reported in the literature (e.g., Bulbule et al., 2002; Bowen et al., 2005 and Hasanuzzaman et al., 2009) indicating that farmers are actually overusing $\mathrm{N}$ fertilizer.

However, since adoption of UDP technology is labour intensive, use of hired labour is significantly higher in both seasons as compared with conventional urea users $(p<0.01)$. The use of family supplied male labour is also significantly higher for the UDP technology adopters in

\footnotetext{
${ }^{2}$ In this study, inputs that contain zero values for some observations are specified as $\ln \left\{\max \left(X_{j}, 1-D_{j}\right)\right\}$ following Battese and Coelli (1995).
} 
both seasons $(p<0.01)$. But for the family supplied female labour, the scenario is opposite. Although this finding is consistent with IFDC reports $(2009,2013)$ that the adoption of UDP technology also increases employment, the extent of actual gain is only 4.5 person days/ha in Boro season and none in Aman season as compared to 9.5 person days/ha reported by IFDC (2009).

Overall, the net returns from MV rice production by UDP technology adopters are significantly higher $(\mathrm{p}<0.01)$ than the conventional urea users (Table 1$)$. The BCR is estimated at 1.36 and 1.08 for MV Boro and MV Aman rice for UDP technology adopters whereas for conventional urea users the BCR is estimated at 1.17 and 0.99 (i.e., a marginal loss), respectively. This finding confirms that in addition to productivity advantage, profitability of UDP technology adoption in rice production is significantly higher than the conventional urea users for both seasons.

\subsection{Productivity effects of UDP technology}

The summary statistics of the variables used in the econometric model is presented in Table 2 . The average age of the farmers is 44.7 years. The average level of education is above primary level (i.e., 6.2 completed years of schooling) and $57.9 \%$ of total household income is derived from non-crop and non-agricultural sources. Only $28.3 \%$ of the farmers are tenants and the use of female labour is substantial ( $42.1 \%$ of total labour use). We see that $38.0 \%$ and $54.0 \%$ of all farmers also applied ashes and organic manure in rice production.

Parameter estimates of the stochastic production frontier along with inefficiency effect model (i.e., Model 1 and Model 2) are reported in Table 4 using the Maximum Likelihood Estimation (MLE) procedure in STATA Version 10 (STATA Corp, 2008). Prior to reporting the results of the SFA model, we report the results of a series of hypothesis tests in Table 3. First we checked the sign of the third moment and the skewness of the Ordinary Least Squares (OLS) residuals of the data in order to justify the use of the stochastic frontier framework (and hence the MLE procedure) ${ }^{3}$. The computed value of Coelli's (1995) standard normal skewness statistic (M3T) based on the third moment of the OLS residuals is $2.85(\mathrm{p}<0.05) \mathrm{H}_{0}: \mathrm{M} 3 \mathrm{~T}=0$. In other words, the null hypothesis of no inefficiency component is rejected and, therefore, use of the stochastic frontier framework is justified (Table 3). The significant value of the coefficient on $\gamma$ reported at the bottom panel of in Table 4 also suggests presence of technical inefficiency.

The coefficients on the input variables have the expected positive sign (i.e., positive marginal products) except organic manure and most of the coefficients are significantly different from zero implying that these inputs jointly increase rice output significantly (Table 4). The negative sign on the coefficient of organic manure, however, implies overuse of this input which should be avoided. Since Cobb-Douglas model is used, the coefficients can be directly interpreted as production elasticities. Table 4 shows that land is the most important determinant of rice production followed by TSP fertilizer and urea, as expected. The elasticity value of land is 0.46-0.47 in two models indicating that a one percent increase in land area will raise rice output by $0.46-0.47 \%$. This figure is almost identical to the elasticity estimate of 0.48 for rice production in Bangladesh reported by Wadud and White (2000). Accounting for zero use of some non-conventional fertilizers and organic manures proved to be worthwhile as the null hypothesis $\left(\mathrm{H}_{0}: \mathfrak{l}_{1}=\mathfrak{1}_{2}=\ldots=\mathfrak{1}_{4}=0\right)$ is strongly rejected at $1 \%$ level of significance (Table 3 )

\footnotetext{
${ }^{3}$ In the stochastic frontier framework, the third moment is also the third sample moment of the $u_{i}$. Therefore, if it is negative, it implies that the OLS residuals are negatively skewed and technical inefficiency is present.
} 
thereby providing confidence that the coefficient estimates of fertilizers reported in Table 4 are corrected for non-use of these inputs by some farmers in the sample.

Coming to our variable of interest, Model 1 of Table 4 clearly shows that the adoption of UDP technology significantly increases rice productivity $(p<0.01)$ which econometrically confirms its yield advantage observed in Table 1. The value of the coefficient on the UDP dummy variable is 0.13 which implies that the rice output obtained by UDP technology users is $13 \%$ higher than the conventional urea users on average.

The sum of the coefficients of the input variables provides a measure of the returns to scale (RTS) which is estimated at 0.98 in both models. The null-hypothesis of constant RTS $\left(\mathrm{H}_{0}\right.$ : $\Sigma \beta_{\mathrm{j}}=1$ for all $\mathrm{j}$ ) cannot be rejected, implying that rice production system exhibits constant RTS in Bangladesh (Table 3). This is in contrast with results from Asadullah and Rahman (2009) and Wadud and White (2000) who reported decreasing RTS. Observation of constant RTS implies that rice production will increase at a constant rate with corresponding increases in inputs.

\subsection{Efficiency effects of UDP technology}

The technical efficiency distribution of farmers is presented in Table 5. Overall, the mean technical efficiency levels of MV rice farmers is estimated at $87 \%$ implying that the production of rice can be increased by $13 \%$ by eliminating inefficiencies. However, Table 5 also clearly shows that the UDP technology adopters are producing at a significantly higher level of technical efficiency estimated at $93 \%$ which is 12 points higher than the technical efficiency levels of conventional urea users estimated at $81 \%(\mathrm{p}<0.01)$. It should be emphasized that the mean technical efficiency estimate of $93 \%$ in rice production by UDP technology adopters is much higher than the previous estimates for Bangladesh (e.g., Wadud and White, 2000; Coelli et al., 2002; Balcombe et al., 2007; Asadullah and Rahman, 2009) as well as those observed in the wider literature estimated at $72.4 \%$ (Bravo-Ureta et al., 2007). The implication is that with the adoption of UDP technology in rice production, farmers are able to eliminate technical inefficiency substantially.

The predictors of technical inefficiency are presented at the lower panel of Table 4 (Model 2). The joint test of hypothesis of no inefficiency effects $\left(\mathrm{H}_{0}: \delta_{1}=\delta_{2}=\ldots .=\delta_{6}=0\right.$ ) was strongly rejected at $1 \%$ level of significance (Table 3 ). Table 4 clearly shows that the UDP technology adopters are relatively technically efficient as compared with the conventional urea users, which econometrically confirms the results reported in Table 5. The value of the coefficient on the UDP dummy variable in the inefficiency effects function in Model 2 (Table 4) implies that the UDP farmers are $14 \%$ less technically inefficient than the conventional urea users on average. The improvement in technical efficiency is largely obtained through significantly less use of $\mathrm{N}$ fertilizer while improving rice productivity at the same time.

Table 5 also shows that the farmers who have other income sources are relatively inefficient. This is consistent with the findings of Rahman (2003) who reported that farmers with higher opportunity to engage in off-farm work fail to pay attention in crop production as compared to other farmers. The results also show that higher ratio of female labour increases inefficiency. This is in contrast with Rahman (2010) who reported that female labour improves technical efficiency. The reason may be due to the type of skills required for UDP technology which the female labourers do not possess. Tenancy status and education seems to have no influence on technical efficiency.

\section{Conclusions and policy implications}


The principle aim of this study was to examine the impacts of UDP technology on profitability, productivity and efficiency in MV rice production at the farm-level, as it holds the promise to economise on a vital, finite and expensive resource (urea fertilizer) while at the same time increase productivity. We have applied standard CBA to estimate profitability of UDP technology adopters and conventional urea users for Boro and Aman seasons and SFA model to determine the impacts of UDP technology on productivity and technical efficiency in MV rice production. Our results clearly establish that the adoption of UDP technology significantly increases profitability, productivity and technical efficiency. The relative gains in yield and net returns from UDP technology adoption are significantly higher in Boro season as compared with Aman season. On average, rice productivity is $13 \%$ higher for UDP farmers and they are $14 \%$ less technically inefficient than the conventional urea users. The mean technical efficiency level of UDP technology adopters in $93 \%$ which is far higher than the figures reported in the literature for rice production. However, the relative yield gains from UDP technology adoption and economy of $\mathrm{N}$ fertilizer use estimated in this study is much lower than those reported from experimental plots in the literature (e.g., Wani et al., 1999; Jaiswal and Singh, 2001; Bulbule et al., 2002; Bowen et al., 2005; Tarfa and Kiger, 2013). Similarly, although the net gain in profitability in Boro season (estimated at USD 232 per ha) is higher than USD 188 per ha reported by IFDC (2009), it is much lower for Aman season estimated at only USD 89 per ha. These findings confirm that the actual gains from the adoption of UDP technology at the farm level is much lower than those reported from experiments at the research stations and, therefore, justifies our motivation to conduct this study.

The policy implication is clear. The UDP technology should be promoted throughout Bangladesh so that the farmers could economise on the use of $\mathrm{N}$ fertilizer and yet significantly improve profitability, productivity and efficiency in MV rice production as evidenced in this study, even though the magnitude of gains are much lower than those obtained from agronomic experiments reported in the literature. Therefore, the ambitious plan undertaken by the government to disseminate UDP technology to 3 million farmers (IFDC, 2009) is a step in the right direction. However, the success of widespread dissemination of this technology will require investments on both elements of this technology: (a) converting commercially available urea into USG through briquetting; and (b) disseminating technological knowhow on the deep placement of USG correctly in the irrigated rice fields at optimum time. According to IFDC (2009), only 2400 briquetting machines are available in Bangladesh in 2009, which is clearly inadequate. Therefore, support is needed to establish small-scale briquetting enterprise throughout Bangladesh. The dissemination of technological knowhow of UDP can be undertaken using mass media and mobile phone technology that is widely available throughout Bangladesh. In fact, the Department of Agricultural Extension and Marketing of the government of Bangladesh has been using national radio and television network to disseminate information on agricultural technologies over the past three decades which need to be further strengthened. Another key policy implication is to invest in developing skills of female agricultural labour so that they can contribute positively in farming. Widespread diffusion of the UDP technology with adequate support services holds the promise to sustain rice production and improve food security in Bangladesh. 


\section{Reference}

Aigner, D., Lovell, C.A.K., Schmidt, P. 1977. 'Formulation and Estimation of Stochastic Frontier Production Function Models,' Journal of Econometrics 6: 21-37.

Alauddin, M., Hossain, M., 2001. Environment and agriculture in a developing economy: Problems and prospects for Bangladesh, Edward Elgar: Cheltenham.

Asadullah, N., Rahman, S. 2009. Farm productivity and efficiency in rural Bangladesh: the role of education revisited. Applied Economics, 41: 17-33.

Balcombe, K., Fraser, I., Rahman, M., Smith, L. 2007. Examining the Technical Efficiency of Rice Producers in Bangladesh, Journal of International Development, 19: 1-16.

Bangladesh Bank, 2010. Annual report, Ministry of Finance, Government of Bangladesh, Dhaka, Bangladesh.

Battese, G.E., Coelli, T.J. 1995. A model for technical inefficiency effects in a stochastic frontier production function for panel data. Empirical Economics, 20, 325-332.

BBS 2011. Bangladesh Bureau of Statistics, Government of Bangladesh, Dhaka, Bangladesh.

BBS 2012. Bangladesh Bureau of Statistics, Government of Bangladesh, Dhaka, Bangladesh.

Bowen, W.T., Diamond, R.B., Singh, U., Thompson, T.P. 2005. Urea deep placement increases yield and saves nitrogen fertilizer in farmers' field in Bangladesh. IFDC, Asia Division. Dhaka-1212, Bangladesh.

Bravo-Ureta, B.E., Solis, D., Lopez, V.H.M., Maripani, J.F., Thiam, A., Rivas, T. 2007. Technical efficiency in farming: a meta regression analysis. Journal of Productivity Analysis, 27: 57-72.

BRRI 2008. Adhunik Dhaner Chash (In Bangla). Bangladesh Rice Research Institute, Gazipur. 14th Edition. pp: 39.

Bulbule, A.V., Purkar, J.K., Jogdande, N.D. 2002 Management of Nitrogen for Rain-fed Transplanted Rice. Crop Research Hisar, 23: 440-445.

Coelli, T., Rahman, S., Thirtle, C. 2002. Technical, allocative, cost and scale efficiencies in Bangladesh rice cultivation: a non-parametric approach. Journal of Agricultural Economics 53: 607-626.

Hasanuzzaman, M., Nahar, K., Alam, M.M., Hossain, M.Z., Islam, M.R. 2009. Response of Transplanted Rice to Different Application Methods of Urea Fertilizer. International Journal of Sustainable Agriculture, 1: 1-5.

Hossain, M. 2002. Rice research and poverty alleviation in Bangladesh, Report No. 2, Centre for Policy Dialogue (CPD), Dhaka.

Hossain, M., Bose, M.L., Mustafi, B. A. A. 2006. Adoption and productivity impact of modern rice varieties in Bangladesh. The Developing Economies, 44: 149-166.

IFDC 2009. Improving efficiency along the agricultural value chain. IFDC Corporate Report 2008/09. Muscle Shoals, Alabama, USA.

IFDC 2013. Fertilizer-Deep-Placement technology. Available @ http://www.ifdc.org/ getattachment/1c7e9b2e37b3-4ea4-93c1-318013dc3ce9/FDP.pdf/ (Accessed November 02, 2014).

Jaiswal, V.P., Singh, G.R. 2001. Performance of Urea Super Granule and Prilled Urea under different planting methods in irrigated rice. Indian Journal of Agricultural Science, 71: 187-189.

Kopp, R.J., Smith, V.K. 1980, Frontier production function estimates for steam electric generation: a competitive analysis. Southern Economic Journal, 47: 1049-1059.

Pasandaran, E., Gultom, B., Adiningsih, J.S., Apsari, H., Rochayati, S. 1999. Government policy support for technology promotion and adoption; A case study of Urea Tablet technology in Indonesia. Nutrition Cycling and Agro-ecosystem, 53: 113-119.

Rahman, S. 2003. Profit efficiency among Bangladeshi rice farmers. Food Policy, 28: 487 - 503.

Rahman, S. 2010. Women's labour contribution to productivity and efficiency in agriculture: empirical evidence from Bangladesh. Journal of Agricultural Economics, 60: 318-342.

Rahman, S., 2002. Technological change and food production sustainability in Bangladesh agriculture. Asian Profile 30, 233-246.

Rahman, S., Hasan, M.K. 2008. Impact of environmental production conditions on productivity and efficiency: the case of wheat producers in Bangladesh. Journal of Environmental Management, 88: 1495-1504. doi:10.1016/j/jenvman.2007.07.019

Rahman, S., Rahman, M.S., Rahman, M.H. 2012. Joint determination of the choice of growing season and economic efficiency of maize in Bangladesh. Journal of the Asia Pacific Economy, 17: 138-150.

STATA Corp, 2008. STATA Version 10. Stata Press Publications, College Station, Texas, USA.

Tarfa, B., Kiger, B. 2013. UDP and Rice production in Nigeria: The experience so far. Conference on Guiding Investments in Sustainable Intensification in Africa (GISAIA), organised by International Fertilizer Development Corporation (IFDC) held in Abuja, Nigeria - June18, 2013. (Powerpoint presentation). 
Wadud, A., White, B. 2000. Farm Household Efficiency in Bangladesh: A Comparison of Stochastic Frontier and DEA Methods. Applied Economics 32: 1665-1673.

Wani, A.R., Hasan, B., Bali, A.S. 1999. Relative efficiency of some modified urea materials in transplanted rice under temperate conditions of Kashmir Division. Agricultural Science and Technology, 36: 382-383.

World Bank, 2014. Arable land (hectares per person) (Available @ http://data.worldbank.org/indicator/ AG.LND.ARBL.HA.PC (Accessed November 01, 2014)

World Bank, 2014. Population density (people per sq. km of land area). Available @ http://data.worldbank.org/indicator/EN.POP.DNST (Accessed November 01, 2014) 
TABLE 1. COSTS AND RETURNS OF PER HECTARE OF RICE PRODUCTION OF UDP USERS AND CONVENTIONAL UREA USERS

\begin{tabular}{lrrrr}
\hline Particulars & & Boro season & & Aman season \\
& UDP with & Normal & UDP with & Normal urea \\
& USG & urea & USG & \\
\hline Yield of rice (kg/ha) & $\mathbf{7 1 6 4 . 0}$ & $\mathbf{6 4 7 5 . 0}$ & $\mathbf{5 2 4 2 . 0}$ & $\mathbf{4 8 6 5 . 0}$ \\
A. Variable costs of MV rice production & $(\mathrm{BDT})$ & $(\mathrm{BDT})$ & $(\mathrm{BDT})$ & (BDT) \\
$\quad$ Seedling cost & 1586.8 & 1604.0 & 1437.2 & 1507.3 \\
$\quad$ Irrigation cost & 22888.7 & 22581.8 & 7758.0 & 6410.8 \\
$\quad$ Pesticides cost & 2416.9 & 3574.0 & 2239.5 & 2972.2 \\
$\quad$ Ash & 186.9 & 296.3 & 7.5 & Na \\
$\quad$ Manure & 704.1 & 591.8 & 59.3 & Na \\
$\quad$ Chemical fertilizers: & & & & \\
$\quad$ Urea & 3599.6 & 6425.0 & 2751.6 & 4973.9 \\
$\quad$ TSP & 3082.6 & 3109.4 & 2275.7 & 2475.2 \\
$\quad$ MP & 1894.5 & 1682.9 & 1408.9 & 1356.9 \\
$\quad$ Gypsum & 663.2 & 637.9 & 602.5 & 375.2 \\
$\quad$ Zinc & 1593.2 & 1707.2 & 610.5 & 636.9 \\
$\quad$ Labour & & & & \\
$\quad$ Hired male labour & 22679.1 & 19116.3 & 22155.4 & 18547.5 \\
$\quad$ Hired female labour & 88.0 & 2488.1 & 58.4 & 3002.8 \\
$\quad$ Family supplied male labour & 12660.5 & 11481.8 & 12643.8 & 11436.8 \\
$\quad$ Family supplied female labour & 2946.8 & 3205.5 & 2538.5 & 3261.1 \\
B. Fixed cost of MV rice production & & & & \\
$\quad$ Opportunity cost of land or land rent & $29,824.2$ & $29,836.7$ & $28,333.0$ & $28,344.9$ \\
C. Total costs (variable and fixed costs) (A+B) & $\mathbf{1 0 6 , 8 1 5 . 0}$ & $\mathbf{1 0 8 , 3 3 9 . 0}$ & $\mathbf{8 4 , 8 8 0 . 0}$ & $\mathbf{8 5 , 3 0 1 . 0}$ \\
Revenue from rice production & & & & \\
$\quad$ Rice & 131077.2 & 114155.8 & 79604.3 & 72832.2 \\
$\quad$ By-product of rice & 14074.4 & 13085.7 & 12207.5 & 12001.1 \\
D. Total revenue (i)+(ii) & $\mathbf{1 4 5 , 1 5 1 . 6}$ & $\mathbf{1 2 7 , 2 4 1 . 5}$ & $\mathbf{9 1 , 8 1 1 . 8}$ & $\mathbf{8 4 , 8 3 3 . 3}$ \\
E. Net profit (D-C) & $\mathbf{3 8 , 3 3 6 . 4}$ & $\mathbf{1 8 , 9 0 2 . 5}$ & $\mathbf{6 , 9 3 2 . 0}$ & $\mathbf{- 4 6 8 . 1}$ \\
F. Benefit cost ratio (D/C) & $\mathbf{1 . 3 6}$ & $\mathbf{1 . 1 7}$ & $\mathbf{1 . 0 8}$ & $\mathbf{0 . 9 9}$ \\
\hline Notes: $\quad$ & & &
\end{tabular}

Notes: $\quad$ 1US $\$=$ BDT 83.60 in May, 2013.

Source: Field Survey, 2013. 
TABLE 2: DEFINITION, MEASUREMENT AND SUMMARY STATISTICS OF VARIABLES (PER FARM)

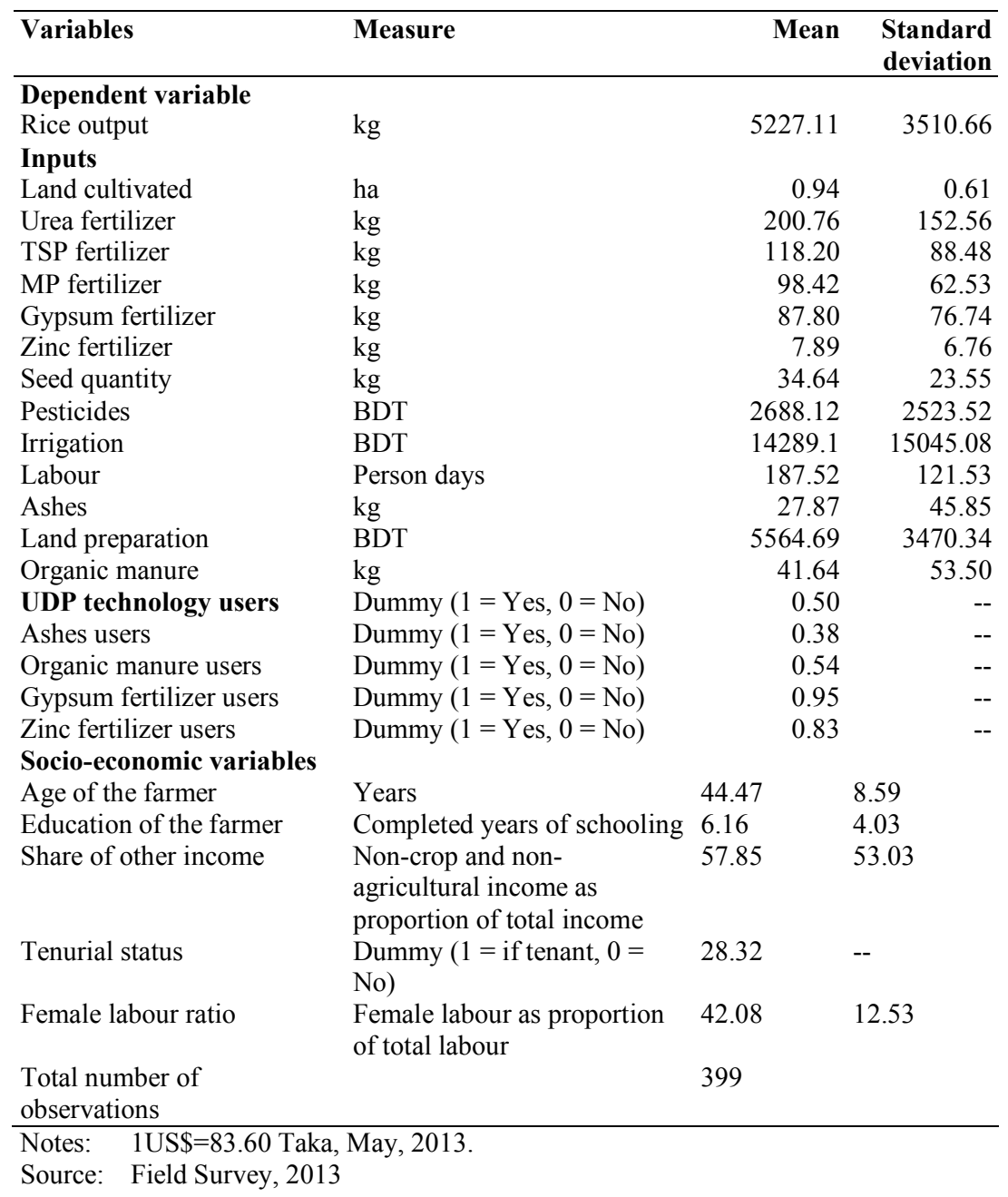


TABLE 3. HYPOTHESIS TESTS

\begin{tabular}{|c|c|c|c|}
\hline Hypotheses & $\begin{array}{r}\text { Critical value of } \\
\chi^{2}(\mathrm{v}, 0.95) \\
\end{array}$ & $\begin{array}{r}\text { Likelihood Ratio } \\
\text { statistic }\end{array}$ & Decision \\
\hline $\begin{array}{l}\text { Frontier test } \\
\left(\mathrm{H}_{0}: \mathrm{M} 3 \mathrm{~T}=0 \text {, i.e., no }\right. \\
\text { inefficiency component })\end{array}$ & $\begin{array}{r}1.96 \\
\text { (z-statistic) }\end{array}$ & $\begin{array}{r}2.85^{* *} \\
\text { (z-statistic) }\end{array}$ & $\begin{array}{r}\text { Reject } \mathrm{H}_{0} \\
\text { Frontier not OLS }\end{array}$ \\
\hline $\begin{array}{l}\text { No effect of users of } \\
\text { fertilizers and organic } \\
\text { manures on productivity } \\
\left(\mathrm{H}_{0}: \mathrm{l}_{1}=\mathrm{l}_{2}=\ldots=\mathrm{l}_{4}=0\right)\end{array}$ & 9.49 & $15.58 * * *$ & $\begin{array}{r}\text { Reject } \mathrm{H}_{0} \\
\text { Significant effect on } \\
\text { productivity }\end{array}$ \\
\hline $\begin{array}{l}\text { Constant returns to scale } \\
\text { in production } \\
\left(\mathrm{H}_{0}: \Sigma \beta_{\mathrm{i}}=1 \text { for all } \mathrm{j}\right)\end{array}$ & 2.71 & 0.68 & $\begin{array}{r}\text { Accept } \mathrm{H}_{0} \\
\text { Constant returns to scale } \\
\text { in production }\end{array}$ \\
\hline $\begin{array}{l}\text { No effect of socio- } \\
\text { economic characteristics } \\
\text { on inefficiency } \\
\left(\mathrm{H}_{0}: \delta_{1}=\delta_{2}=\ldots .=\delta_{6}=\right. \\
0)\end{array}$ & 12.59 & $74.05 * * *$ & $\begin{array}{r}\text { Reject } \mathrm{H}_{0} \\
\text { Inefficiencies are jointly } \\
\text { explained by these } \\
\text { variables }\end{array}$ \\
\hline $\begin{array}{l}* * * \text { si } \\
* * \\
* *\end{array}$ & $\begin{array}{l}\% \text { level }(\mathrm{p}<0.01) \\
\text { o level }(\mathrm{p}<0.05)\end{array}$ & & \\
\hline
\end{tabular}


TABLE 4: JOINT PARAMETER ESTIMATES OF THE STOCHASTIC PRODUCTION FRONTIER WITH INEFFICIENCY EFFECTS MODEL

\begin{tabular}{|c|c|c|c|c|c|}
\hline \multirow[t]{2}{*}{ Variables } & \multirow[t]{2}{*}{ Parameter } & \multicolumn{3}{|c|}{ Model 1} & \multirow{2}{*}{$\frac{\text { Model } 2}{\text { t-ratio }}$} \\
\hline & & Coefficient & t-ratio & Coefficient & \\
\hline \multicolumn{6}{|l|}{$\begin{array}{l}\text { Stochastic production } \\
\text { frontier model }\end{array}$} \\
\hline Constant & $\beta_{0}$ & $5.3261 * * *$ & 13.31 & $5.5916 * * *$ & 13.98 \\
\hline Land cultivated & $\beta_{1}$ & $0.4554 * * *$ & 8.31 & $0.4703 * * *$ & 8.47 \\
\hline Urea fertilizer & $\beta_{2}$ & $0.0681 * * *$ & 2.49 & $0.0883 * * *$ & 3.28 \\
\hline TSP fertilizer & $\beta_{3}$ & $0.1165 * * *$ & 3.66 & $0.1370 * * *$ & 4.28 \\
\hline MP fertilizer & $\beta_{4}$ & $0.0483 *$ & 1.72 & $0.0473 *$ & 1.64 \\
\hline Gypsum fertilizer & $\beta_{5}$ & 0.0117 & 0.61 & 0.0070 & 0.36 \\
\hline Zinc fertilizer & $\beta_{6}$ & $0.0535 * * *$ & 3.03 & $0.0489 * * *$ & 2.70 \\
\hline Pesticides & $\beta_{7}$ & $0.0259 * * *$ & 2.60 & $0.0291 * * *$ & 2.80 \\
\hline Irrigation & $\beta_{8}$ & $0.0802 * * *$ & 6.08 & $0.0723 * * *$ & 5.50 \\
\hline Labour & $\beta_{9}$ & 0.0412 & 1.18 & 0.0218 & 0.65 \\
\hline Ashes & $\beta_{10}$ & 0.0082 & 0.71 & 0.0011 & 0.10 \\
\hline Land preparation & $\beta_{11}$ & $0.0987 * * *$ & 2.93 & $0.0817 * * *$ & 2.38 \\
\hline Organic manure & $\beta_{12}$ & $-0.0229 * *$ & -2.06 & $-0.0216^{*}$ & -1.94 \\
\hline UDP technology users & $\alpha_{1}$ & $0.1347 * * *$ & 6.22 & -- & -- \\
\hline Ashes users & $\tau_{2}$ & 0.0139 & 0.28 & 0.0497 & 1.00 \\
\hline Organic manure users & $\tau_{3}$ & $0.1356 * * *$ & 2.76 & $0.1213 * * *$ & 2.46 \\
\hline Gypsum fertilizer users & $\tau_{4}$ & -0.0258 & -0.30 & -0.0037 & -0.04 \\
\hline Zinc fertilizer users & $\tau_{5}$ & $-0.0908 * *$ & -2.43 & $-0.0778 * *$ & -2.08 \\
\hline \multicolumn{6}{|l|}{ Variance Parameters } \\
\hline$\sigma^{2}=\sigma_{u}^{2}+\sigma_{v}^{2}$ & $\sigma^{2}$ & 0.0289 & 1.6507 & -- & -- \\
\hline $\begin{array}{l}\gamma=\sigma_{u}^{2} /\left(\sigma_{u}^{2}+\sigma_{v}^{2}\right) \\
\text { Log likelihood }\end{array}$ & $\gamma$ & 0.7564 & 3.2612 & -- & -- \\
\hline Wald $\chi^{2}(17 \mathrm{df})$ & $\chi^{2}$ & 12137.19 & & -- & -- \\
\hline \multicolumn{6}{|l|}{$\begin{array}{l}\text { Inefficiency effects } \\
\text { function }\end{array}$} \\
\hline Constant & $\delta_{0}$ & -1.0051 & -0.73 & $0.1452 * *$ & 2.18 \\
\hline Age of the farmer & $\delta_{1}$ & 0.0030 & 0.50 & 0.0006 & 0.95 \\
\hline Education of the farmer & $\delta_{2}$ & -0.0066 & -0.49 & -0.0014 & -1.04 \\
\hline Share of other income & $\delta_{3}$ & $0.1245^{* *}$ & 1.96 & $0.0466 * * *$ & 4.43 \\
\hline Tenurial status & $\delta_{4}$ & -0.2032 & -0.64 & -0.0157 & -1.38 \\
\hline Female labour ratio & $\delta_{5}$ & 1.1099 & 0.85 & $0.0798^{*}$ & 1.79 \\
\hline UDP technology users & $\delta_{6}$ & -- & -- & $-0.1438 * * *$ & -6.54 \\
\hline Total number of & & 399 & & 399 & \\
\hline
\end{tabular}

\begin{tabular}{ll}
\hline Note: & $* * *$ significant at $1 \%$ level $(\mathrm{p}<0.01)$ \\
& $* *$ significant at $5 \%$ level $(\mathrm{p}<0.05)$ \\
& $*$ significant at $10 \%$ level $(\mathrm{p}<0.10)$
\end{tabular} 
TABLE 5: TECHNICAL EFFICIENCY DISTRIBUTION

\begin{tabular}{lr}
\hline Items & $\begin{array}{r}\text { Percentage of farmers } \\
\text { (Model 2) }\end{array}$ \\
\hline Efficiency levels & 0.50 \\
up to $70 \%$ & 18.00 \\
$71-80 \%$ & 37.10 \\
$81-90 \%$ & 44.40 \\
$91 \%$ and above & \\
Mean efficiency by UDP technology & \\
adoption & 0.93 \\
UDP technology users & 0.81 \\
Conventional urea users & \\
Overall & 0.87 \\
Mean efficiency score & 0.07 \\
Standard deviation & 0.64 \\
Minimum & 0.99 \\
Maximum &
\end{tabular}

